Volume 2, Issue 1, pages 75-88

p-ISSN 2655-8564, e-ISSN 2685-9432

\title{
Smart Campus Mobile Application Toward the Development of Smart Cities
}

\author{
Tanweer Alam ${ }^{1, *}$, Yazeed Mohammed Alharbi ${ }^{1}$, Firas Adel \\ Abusallama ${ }^{1}$, Ahmad Osama Hakeem ${ }^{1}$ \\ ${ }^{1}$ Department of Computer Science, Faculty of Computer and Information \\ Systems, Islamic University of Madinah, Saudi Arabia \\ *Corresponding Author: tanweer03@iu.edu.sa
}

(Received 23-01-2020; Revised 09-02-2020; Accepted 09-02-2020)

\begin{abstract}
Smart Campus is an android mobile application that has strong features to facilitates students, faculties, admins, parents, and managers. It provides a comprehensive integrated solution to improve the overall performance of the college. The use of mobile applications is increasing day by day. We all use the mobile application in a lot of things in our daily life. We came up with an idea of building an application that will help the students and faculty member to accesses the system as fast as possible. In this study, we will discuss the problem and propose a solution to it, as we will talk about the planning phase and its component, requirements the functional and nonfunctional with its Data Flow Diagram, etc. We also design the interfaces. This mobile application will help the students and faculty members to do the tasks in the minimum time.
\end{abstract}

Keywords: mobile application, android, smart campus, smart cities. 


\section{International Journal of Applied Sciences and Smart Technologies}

Volume 2, Issue 1, pages 75-88

p-ISSN 2655-8564, e-ISSN 2685-9432

\section{Introduction}

The problem in this situation is about time if you want to check in the system you have to go to the browser, next search about the university, then looking for the page to help for go on the system put if we have an application we will shortcut a lot of steps to go on it. After we studied the problem and knowing the student's and faculty member's needs [1]. We decided to create a mobile application that will serve those who need to do his tasks such as check the schedule, add and remove a course, and many other functions $[18,19]$. Develop a software platform to be able to access the digital college system as fast as possible.

a. Collect requirements about students and faculty members.

b. Analyze the collected requirements and propose solutions to these problems.

c. Attract the largest number of students and faculty members.

d. Students and faculty members can use the system at any time and easy to use.

What makes our application different than the other applications we talked about (Islamic university)? After we installed the application and tested, we explored that application depends on the web page for the Islamic university, it created as an interface $[4,5,6]$. Actually, all icons linked by the web pages there is no database depend on it. For example, if a student wants to show the schedule, he will click on the icon on the academic system then will transfer to the web page for Islamic university $[7,8,9,10]$. Also, the problem with this system is that it is supported only by the Arabic language. That application creates just for the students it does not support faculty members and deans $[11,12,13,14]$. However, in our application, there is a database. It is an independent application that does not depend on web pages. Also, it supports English language. It can use by students, faculty members, and deans.

The rest of the paper is organized as follows. The related works are explained in section 2, the research methodologies are explained in section 3, results and discussion are explained in section 4 , and the conclusion is explained in section 5. 


\section{International Journal of Applied Sciences and Smart Technologies}

Volume 2, Issue 1, pages 75-88

p-ISSN 2655-8564, e-ISSN 2685-9432

\section{Related works}

This article is based on ideas from several experts, including :

1. Imam Muhammad bin Saud University

The official application of the Imam Mohammed bin Saud Islamic University provides application services for many of the employees of the university students, staff, faculty members, visitors, and others $[15,16,17]$. The application provides the most important news and announcements and events about the university in addition to university maps and academic calendar and telephone directory and others [2]. The most important services of students: student information, schedule, grades, exam schedule, etc. The most important services of staff and faculty: salaries - vacations allowances - inboxes. There are obtains as shown in Figure 1.
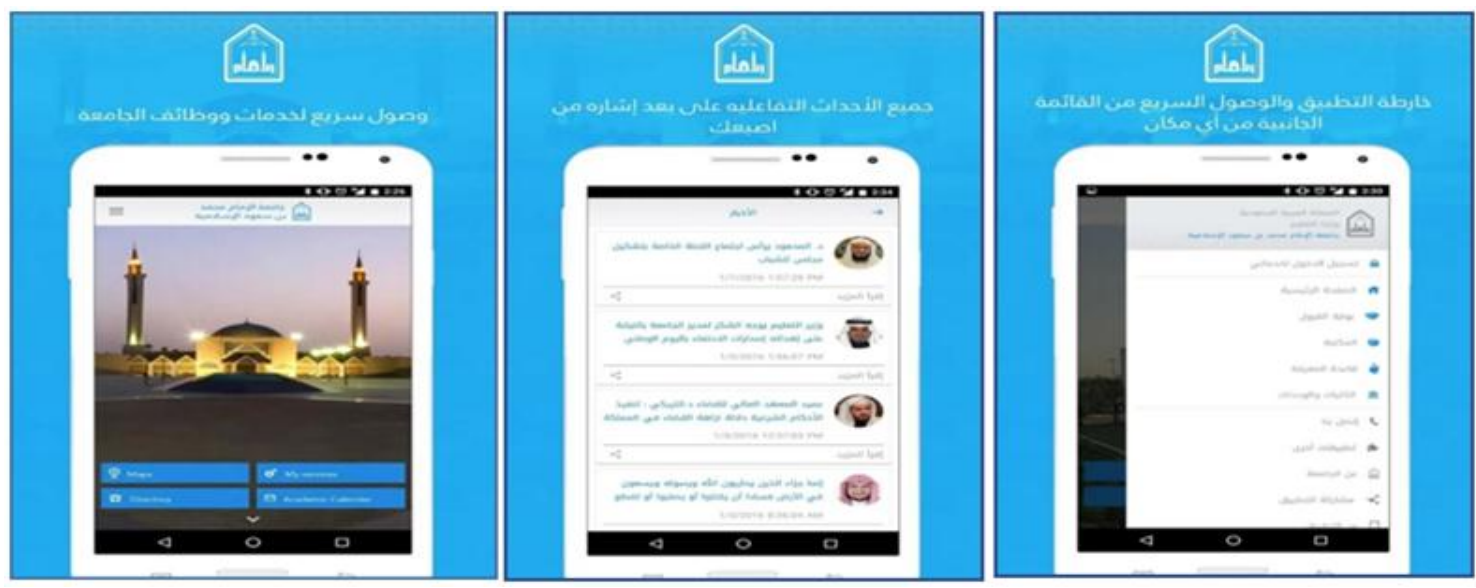

Figure 1. Imam Muhammad bin Saud University

\section{Qassim University Application}

Qaseem University online service in Figure 2 is a mobile application that aim is to provide communication with students, faculties, management etc. Also, students can add, remove courses for their schedule, show marks, transcripts, and plan [3, 19]. 


\section{International Journal of Applied Sciences and Smart Technologies}

Volume 2, Issue 1, pages 75-88

p-ISSN 2655-8564, e-ISSN 2685-9432
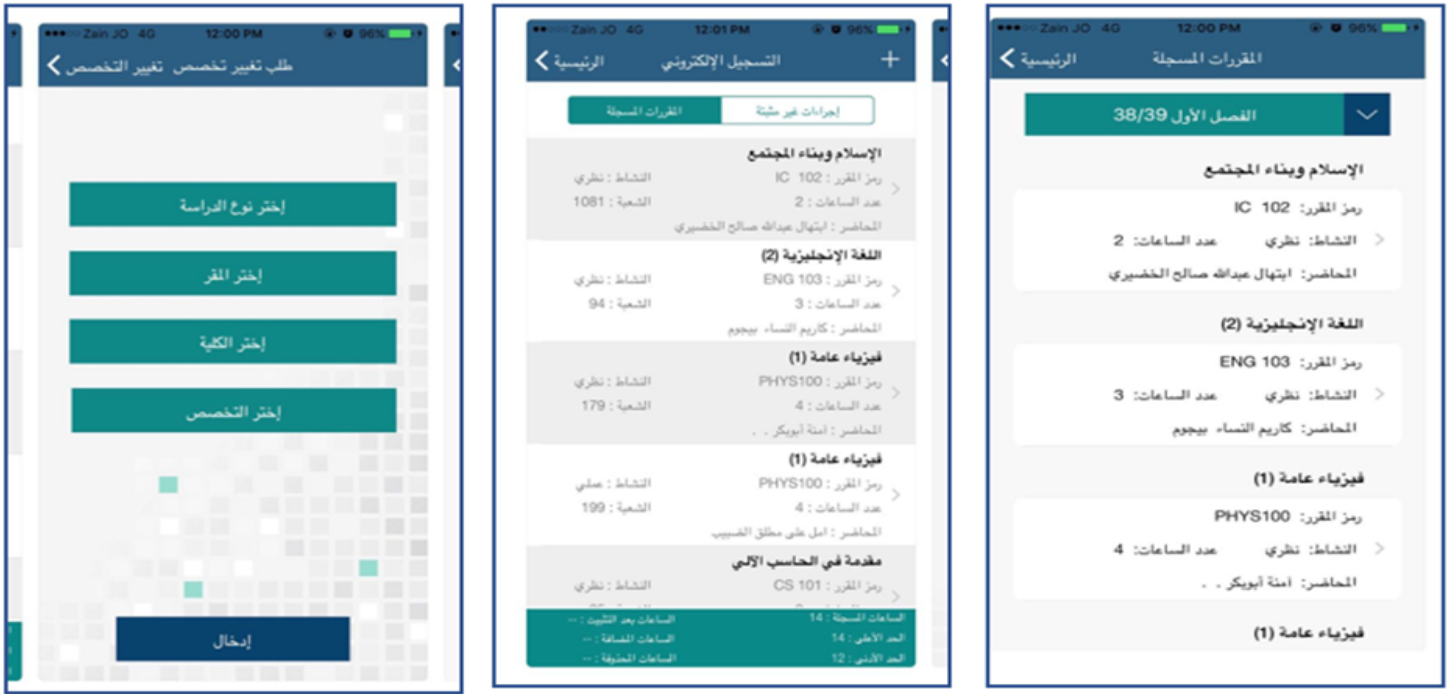

Figure 2. Qassim University application

3. Islamic University Mobile Application:

You can follow through the application in Figure 3 :

a. University news and announcements

b. Access to the university's personal account

c. Booking travel administration dates

d. View the names of the admissions

e. University calendar

f. Follow the requests of the university administration and communicate with the Rector.

g. Save your notes in the application (days and tests)

h. Department of Messages Received 


\section{International Journal of Applied Sciences and Smart Technologies}

Volume 2, Issue 1, pages 75-88

p-ISSN 2655-8564, e-ISSN 2685-9432
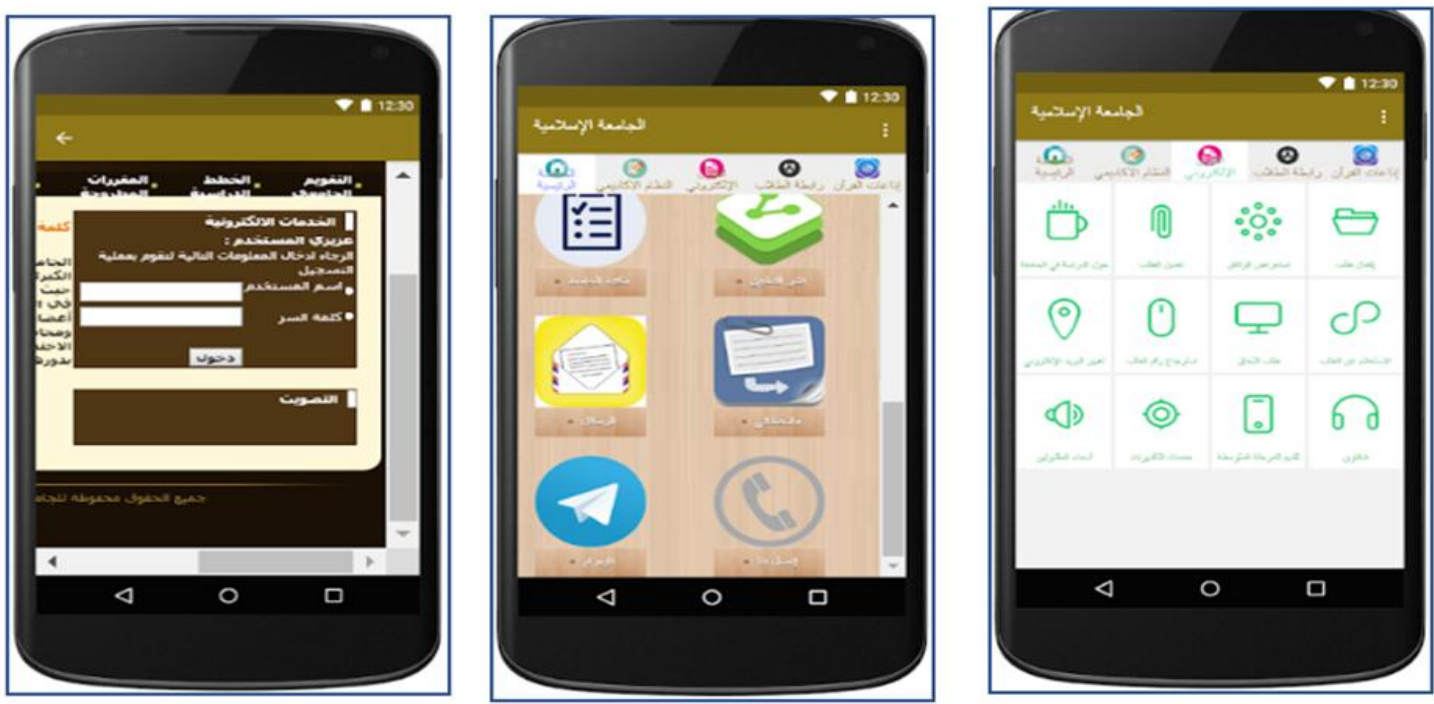

Figure 3. Islamic University.

\section{Research Methodology}

This diagram explains how the user can enter the system we mean by user (Student, Faculty Member, Manager, Admin) when the user opens the application he will enter his user name and password then the application will check with database, the databases response message $[20,21]$ to the application if the user name and password match in the database he will enter to home page otherwise reject. There are obtains as shown in Figure 4 below.

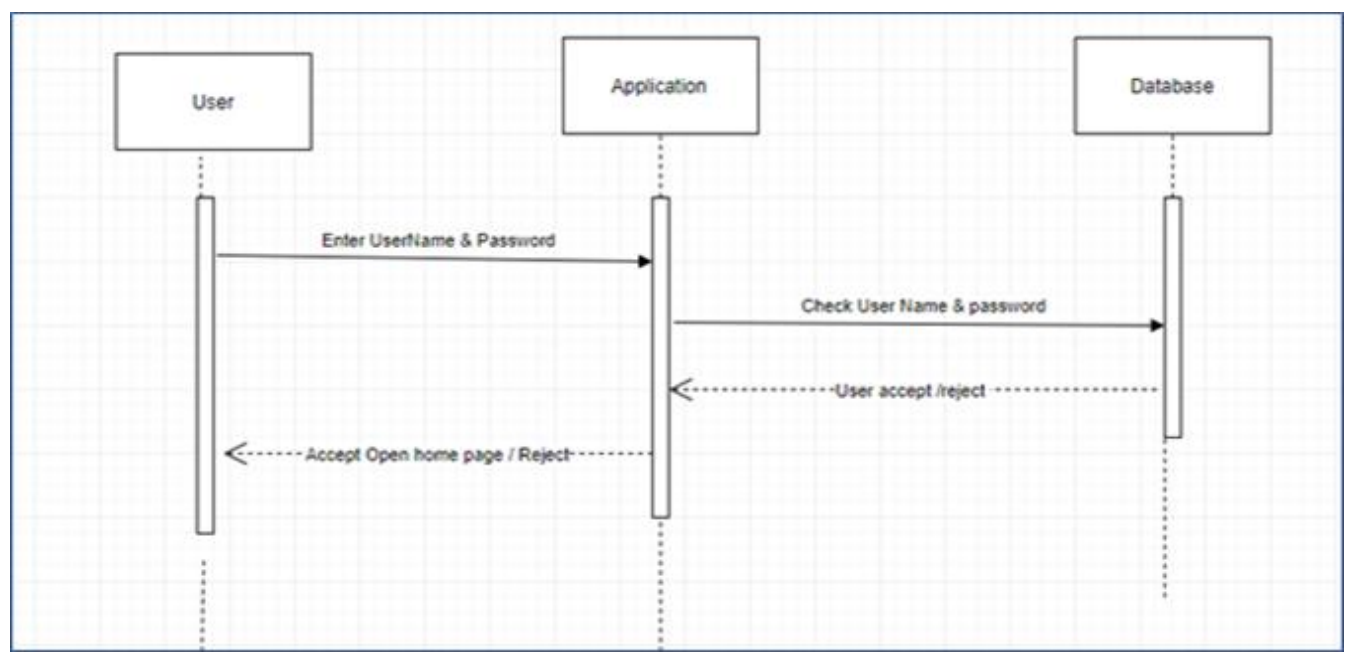

Figure 4. Login to the system 


\section{International Journal of Applied Sciences and Smart Technologies}

Volume 2, Issue 1, pages 75-88

p-ISSN 2655-8564, e-ISSN 2685-9432

In Figure 5 there is the following sequence diagram, show how the admin give approve to account by choose account in the application then give him approve in the database after that the approved account can enter the system

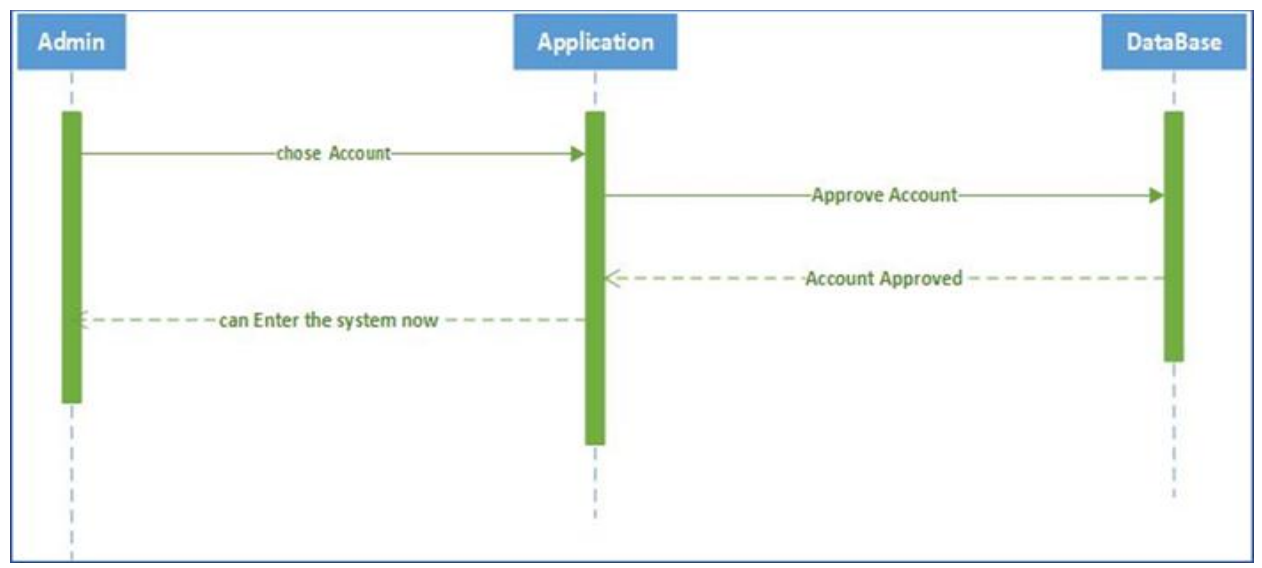

Figure 5. Approve account

The next sequence diagram shows how the student can add or remove a course from his schedule $[22,23]$. If the student wants to add a course first choose course name in the application. It will add the course to the database and the database will response message to the application then the course will be in the student schedule.

Remove course is similar to add the course. The student will choose a course in the application, then the course will be deleted from the database. The database will respond message to the application course removed. Course removed from the student schedule. This is obtains as shown in Figure 6.

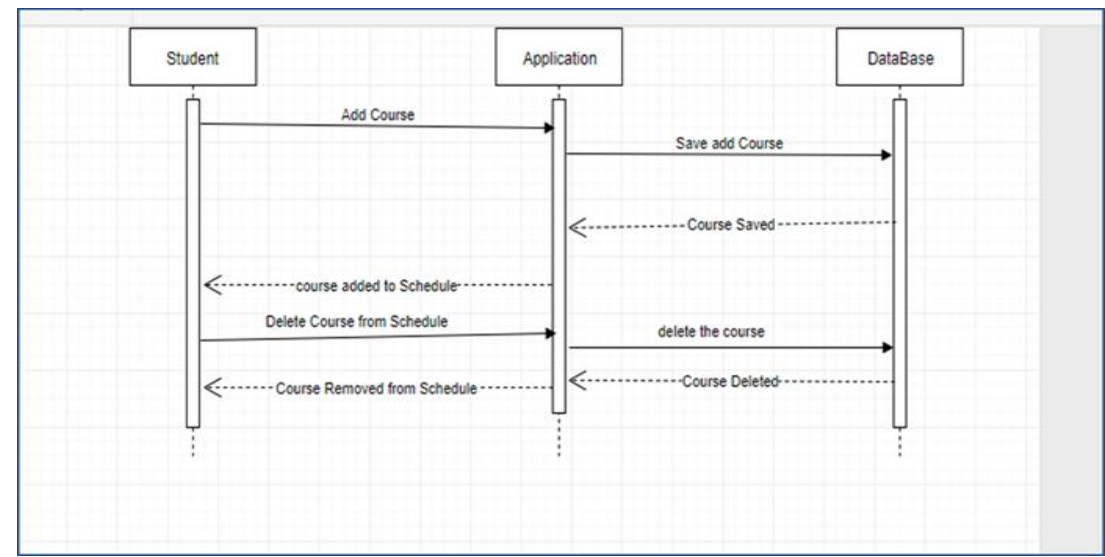

Figure 6. Add/remove course 


\section{International Journal of Applied Sciences and Smart Technologies}

Volume 2, Issue 1, pages 75-88

p-ISSN 2655-8564, e-ISSN 2685-9432

The following diagram explains how the student can evaluate the courses and faculty members through questionaries. After the student selectsa specific course in the application, he will start the evaluation of the course and faculty member and submit the evaluation to the application $[24,25]$. The application in Figure 7 will store the submission in the database. The database will respond message to the application evaluation stored.

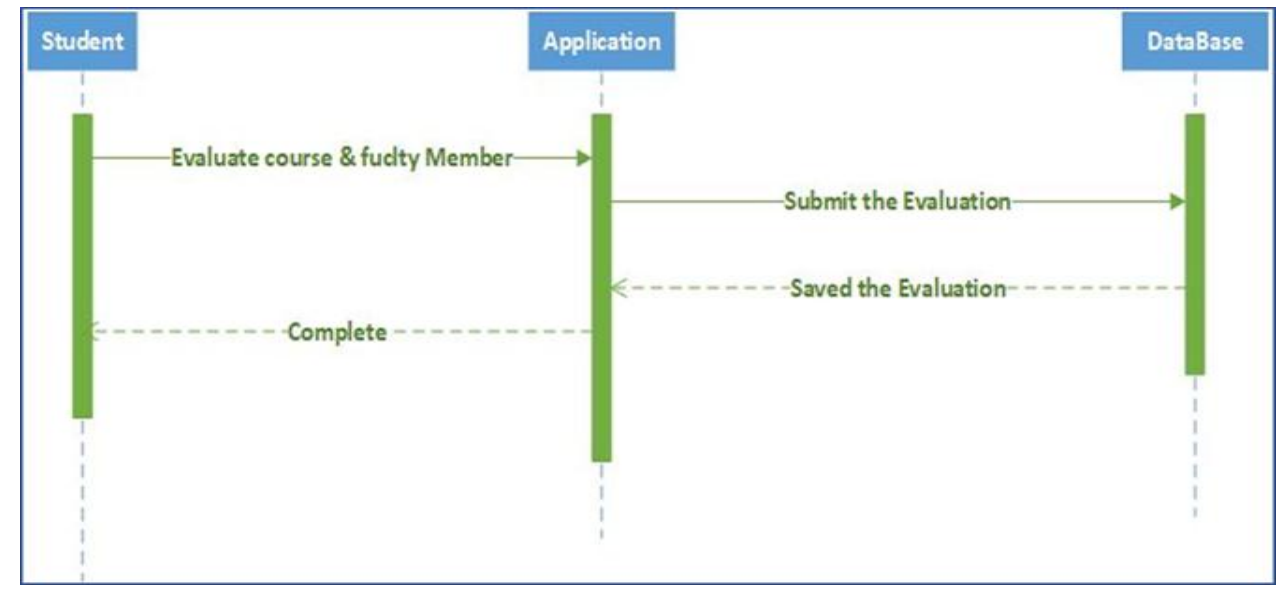

Figure 7. Evaluate course and faculty member

The Following sequence diagram shows how Faculty member set marks for students. After choosingthe student the faculty member can set the marks in the application. The application will store the marks in the database [26, 27, 28]. The database will respondto message marks stored. The application will show the marks in Figure 8.

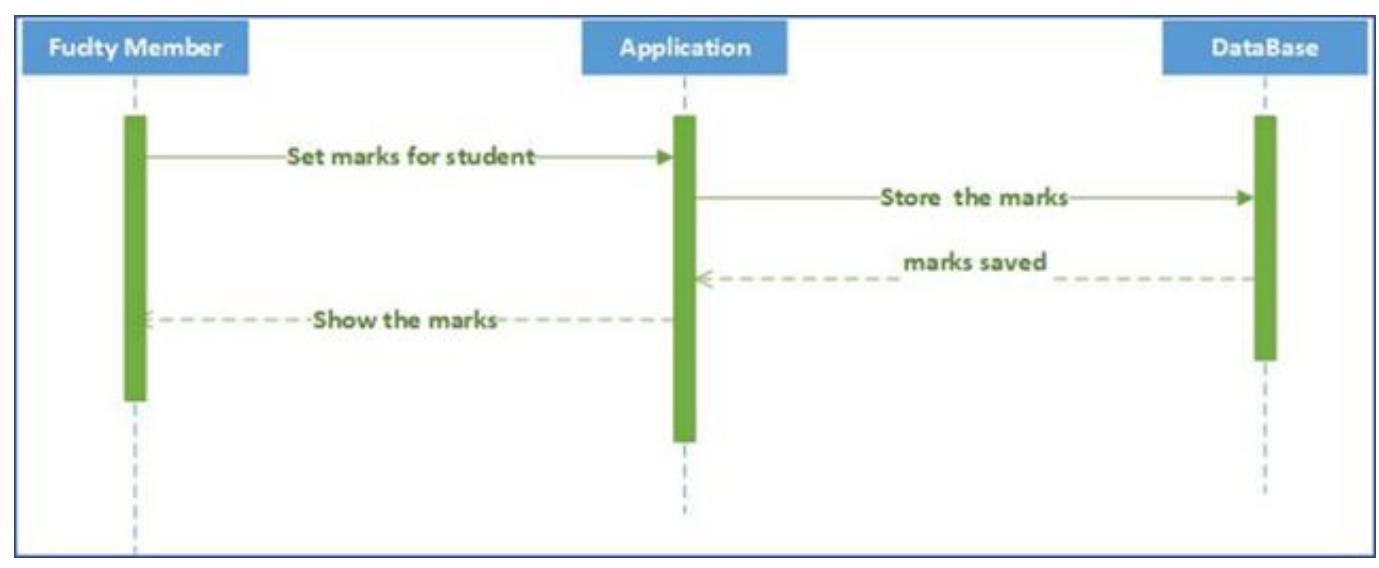

Figure 8. Set marks to student 


\section{International Journal of Applied Sciences and Smart Technologies}

Volume 2, Issue 1, pages 75-88

p-ISSN 2655-8564, e-ISSN 2685-9432

The next diagram shows how a manager can give permission. After selecting students or faculty members and determine the type of permission in the application. The application will update the database. The database will respondto the message the student or faculty member has permission for the application. Students or faculty members can now use the new permission. That is obtains as shown in Figure 9.

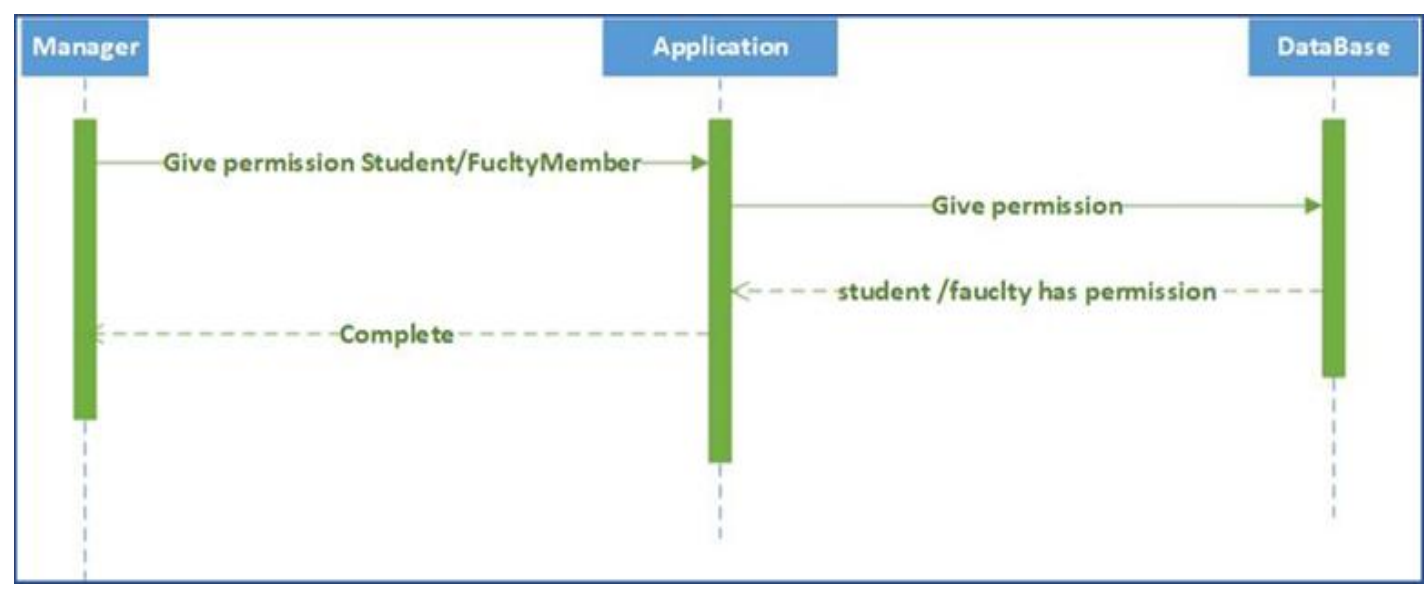

Figure 9. Give permission from the manager

The following sequence diagram in Figure 10 explains how the admin update data. First, the admin will select the user (student, faculty member, manager) and change data in the application $[29,30,31]$. The application will store the data in the database. The database will respond message to the application data updated [32, 33]. The application will show the updated data.

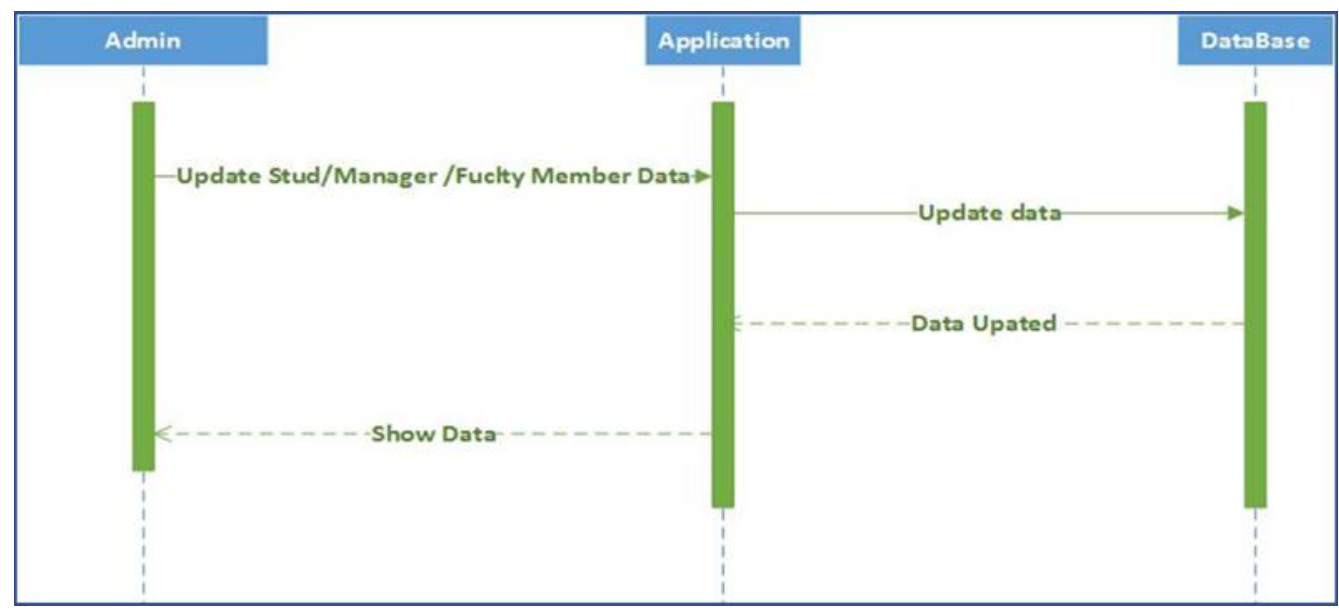

Figure 10.Update data from admin 


\section{International Journal of Applied Sciences and Smart Technologies}

Volume 2, Issue 1, pages 75-88

p-ISSN 2655-8564, e-ISSN 2685-9432

\section{$4 \quad$ Results and Discussions}

The first interface is the login interface.It let the user enter his name and his password to enter into the application. There is a forget password button for the turn to another page to create a new password. In addition, the sing up button for a turn to the page to create new accounts. There are obtains as shown in Figure 11, 12, and 13 below:
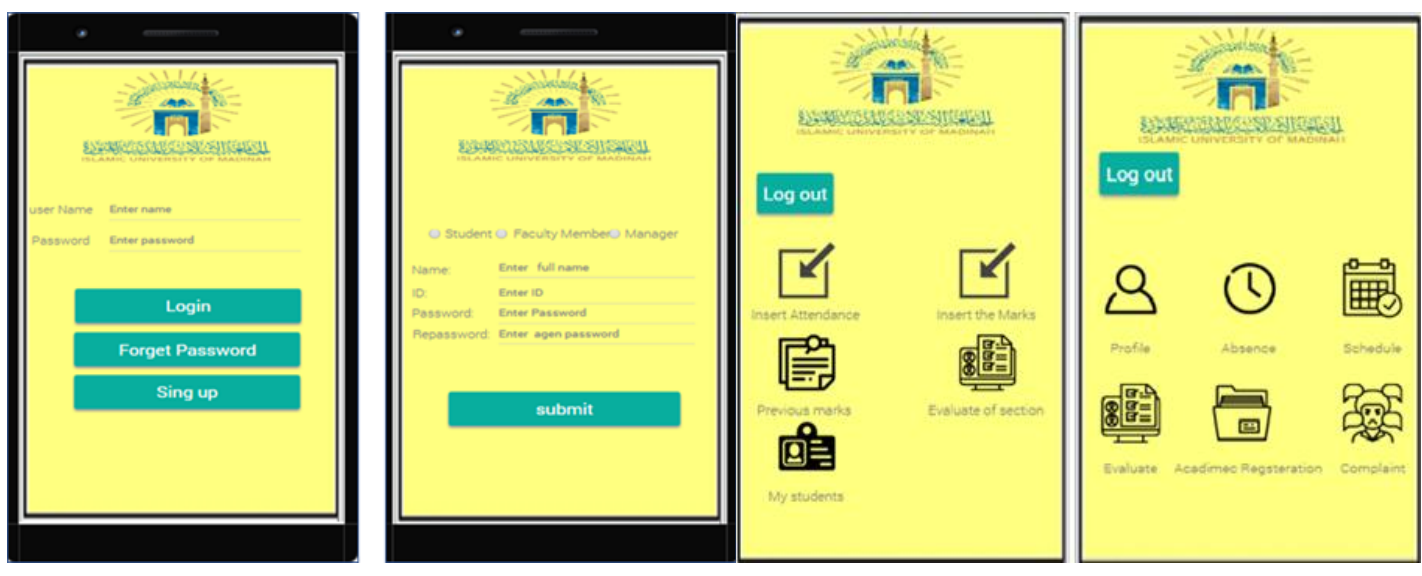

Figure 11. Application interfaces

This is the registry interface and you have the option of choosing between student, faculty, and administrator. To complete registration in the application. Username, password, and repeat password are necessary. This is the main menu interface for a student. There are processes for students such as showing profiles, absence, schedule, and academic registration. Also can do evaluate for the courses. This is the main menu interface for faculty members. There are processes for faculty members such as showing the evaluation of section and previous marks. In addition, they can make some operations such as insert attendance and marks. This is the registry interface and you have the option of choosing between student, faculty, and administrator. To complete registration in the application. Username, password, and repeat password are necessary. This is the main menu interface for a student. There are processes for students such as showing profiles, absence, schedule, and academic registration. Also can do evaluate for the courses. This is the main menu interface for faculty members. There are processes 


\section{International Journal of Applied Sciences and Smart Technologies}

Volume 2, Issue 1, pages 75-88

p-ISSN 2655-8564, e-ISSN 2685-9432

for faculty members such as showing the evaluation of section and previous marks. In addition, they can make some operations such as insert attendance and marks.
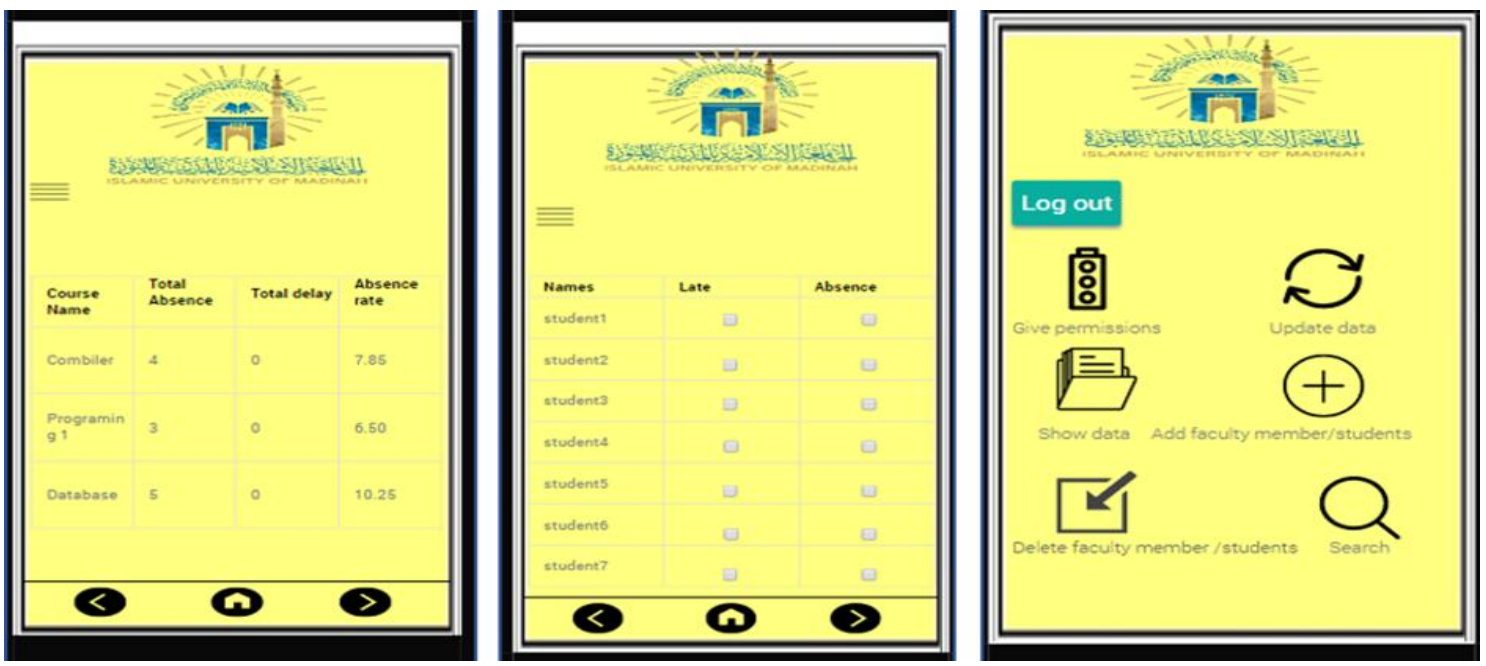

Figure 12.Application interfaces
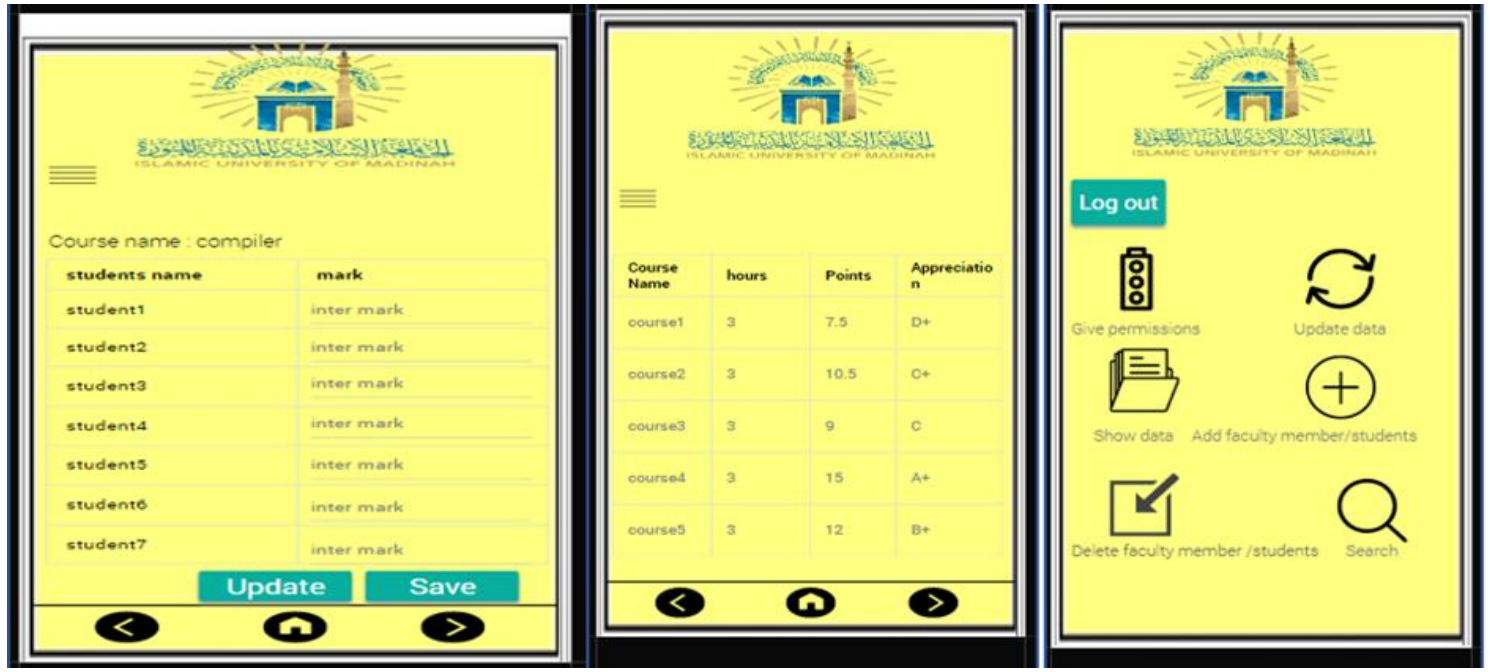

Figure 13.Application interfaces

\section{Conclusions}

The authors have done all the initiation processes that start from problem statement moving through the proposed solution into objectives and the aim. We studied and clarify three of related work that has some similarity of our project, which are 'application of the Imam Mohammed bin Saud University, Qassim University 


\section{International Journal of Applied Sciences and Smart Technologies}

Volume 2, Issue 1, pages 75-88

p-ISSN 2655-8564, e-ISSN 2685-9432

Application, Islamic University Application. Each one of them has one or more properties we are going to use in our application, also they have some negative we must avoid. The survey is done for information gathering from users. We collected the information that we gathered from the survey and we analyzed it, some UML Diagrams and Data Flow Diagrams as well as, the interface at the end. We have worked hard and diligent in this project, and believe we have done very well, and hope that everyone likes and uses our application, and making their life easier, and that's what we've tried to achieve for them.

\section{References}

[1] A Comprehensive Education Management Suite, http://www.auromeera.com/ (Accessed on 10-02-2020).

[2] Al Imam University, https://play.google.com/store/apps/details?id=com. imamuniversity.app\&hl=ar (Accessed on 10-02-2020).

[3] Al Qaseem University, http://cutt.us/uKdaZ (Accessed on 10-02-2020).

[4] A. Tanweer, "5G-Enabled Tactile Internet for smart cities: vision, recent developments, and challenges", Jurnal Informatika, 13 (2), 1 - 10, 2019.

[5] V. R. Ganesh, “Android College Management System”, International Journal of Advanced Research in Computer Engineering \& Technology, 5 (4) 882 - 885, 2016.

[6] N. M. Z. Hashim and S. N. K. S. Mohamed, "Development of Student Information System", International Journal of Science and Research (IJSR), 2 (8), $256-260,2013$.

[7] What is SDLC Waterfall Model ?, http://cutt.us/tHhIF (Accessed on 10-02-2020).

[8] M. Rouse, Requirements analysis, 2007, http://cutt.us/3di7W (Accessed on 10-022020).

[9] U. Eriksson, The difference between functional and non-functional requirements. 2015, http://cutt.us/5ICJ1 (Accessed on 10-02-2020).

[10] Bisk. What is SWOT Analysis? http://cutt.us/XmfjA. (Accessed on 10-02-2020).

[11] Use case diagram, http://cutt.us/sQ4Me (Accessed on 10-02-2020). 


\section{International Journal of Applied Sciences and Smart Technologies}

Volume 2, Issue 1, pages 75-88

p-ISSN 2655-8564, e-ISSN 2685-9432

[12] Islamic university, http://cutt.us/oqDrP (Accessed on 10-02-2020).

[13] Just In Mind, http://cutt.us/1RnZI (Accessed on 10-02-2020).

[14] Sequence Diagram, http://cutt.us/S38IQ (Accessed on 10-02-2020).

[15] A. Tanweer and M. Benaida, "The Role of Cloud-MANET Framework in the Internet of Things (IoT)", International Journal of Online Engineering (iJOE), 14 (12), 97-110, 2018.

[16] A. Tanweer, "Middleware Implementation in Cloud-MANET Mobility Model for Internet of Smart Devices", International Journal of Computer Science and Network Security, 17 (5), 86 -94, 2017.

[17] A. Tanweer and M. Benaida, "CICS: Cloud-Internet Communication Security Framework for the Internet of Smart Devices", International Journal of Interactive Mobile Technologies (IJIM). 12 (6), 74-84, 2018

[18] A.Tanweer and B. Rababah, "Convergence of MANET in Communication among Smart Devices in IoT", International Journal of Wireless and Microwave Technologies(IJWMT), 9 (2), 1-10, 2019.

[19] A. Tanweer, "IoT-Fog: A Communication Framework using Blockchain in the Internet of Things", International Journal of Recent Technology and Engineering (IJRTE), 7 (6), 2019.

[20] A. Tanweer, "Blockchain and its Role in the Internet of Things (IoT)", International Journal of Scientific Research in Computer Science, Engineering and Information Technology, 5 (1), 151-157, 2019.

[21] A. Tanweer, "A reliable framework for communication in internet of smart devices using IEEE 802.15.4”, ARPN Journal of Engineering and Applied Sciences, 13 (10), 3378-3387, 2018.

[22] A. Tanweer, "A Reliable Communication Framework and Its Use in Internet of Things (IoT)", International Journal of Scientific Research in Computer Science, Engineering and Information Technology (IJSRCSEIT), 3 (5), 450-456, 2018.

[23] A. Tanweer and M. Aljohani, "Design and implementation of an Ad Hoc Network among Android smart devices", Green Computing and Internet of Things (ICGCIoT), 1322-1327, 2015. 


\section{International Journal of Applied Sciences and Smart Technologies}

Volume 2, Issue 1, pages 75-88

p-ISSN 2655-8564, e-ISSN 2685-9432

[24] A. Tanweer and M. Aljohani, "An approach to secure communication in mobile ad-hoc networks of Android devices", International Conference on Intelligent Informatics and Biomedical Sciences (ICIIBMS), 371-375, 2015.

[25] M. Aljohani and A. Tanweer, "An algorithm for accessing traffic database using wireless technologies", Computational Intelligence and Computing Research (ICCIC), IEEE International Conference, 1-4, 2015.

[26] A. Tanweer and M. Aljohani, "Design a new middleware for communication in ad hoc network of android smart devices", Proceedings of the Second International Conference on Information and Communication Technology for Competitive Strategies, 1-6, 2016.

[27] A. Tanweer, "Fuzzy control based mobility framework for evaluating mobility models in MANET of smart devices", ARPN Journal of Engineering and Applied Sciences, 12 (15) , 4526-4538, 2017.

[28] A. Tanweer, A. P. Srivastava, S.Gupta and R. G. Tiwari, "Scanning the Node Using Modified Column Mobility Model”, Computer Vision and Information Technology: Advances and Applications, 455, 2010.

[29] A. Tanweer and B. K. Sharma, “A New Optimistic Mobility Model for Mobile Ad Hoc Networks", International Journal of Computer Applications, 8 (3), 1-4, 2010 .

[30] A. Tanweer, "Cloud Computing and its role in the Information Technology", IAIC Transactions on Sustainable Digital Innovation (ITSDI), 1 (2), 108 - 115. 2020 .

[31] A. Tanweer, A. S. Salem, A. O. Alsharif, and A. M. Alhejaili, "Smart Home Automation Towards the Development of Smart Cities", APTIKOM Journal on Computer Science and Information Technologies, 5 (1).2020.

[32] M. Aljohani and A. Tanweer, "Design an M-learning framework for smart learning in ad hoc network of Android devices," Proceedings of Computational Intelligence and Computing Research, IEEE International Conference on, 1 - 5, 2015. 
International Journal of Applied Sciences and Smart Technologies

Volume 2, Issue 1, pages 75-88

p-ISSN 2655-8564, e-ISSN 2685-9432

[33] M. Aljohani and A. Tanweer. "Real Time Face Detection in Ad Hoc Network of Android Smart Devices", Advances in Computational Intelligence : Proceedings of International Conference on Computational Intelligence.245 - 2552015. 